\section{'There has NEVER been a better time to train as an DHE'}

\section{Elizabeth Hill describes life as an oral health educator.}

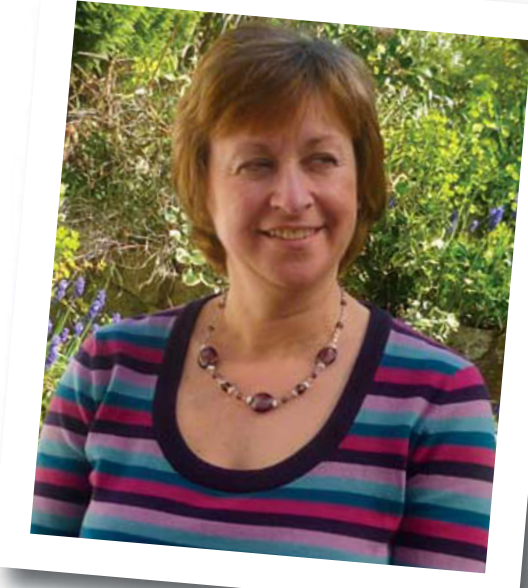

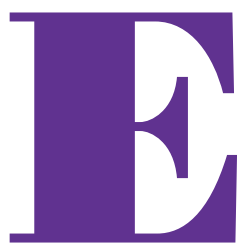

lizabeth started her career as a dental nurse. After taking the NEBDN certificate in Oral Health Education, she went on to take her teaching certificate, and is now

an OHE-Southwest tutor as well as the practice manager of four dental practices.

\section{Increasingly important}

Trained oral health educators (OHEs) are becoming an increasingly important part of practice life, educating patients to achieve a higher standard of oral health in a friendly, open way, and in language that they understand. But what is life really like for dental nurses and other dental care professionals (DCPs) after they have qualified as OHEs?

\section{Darlings of dentistry}

Ann Felton, founder of the Bristol and Plymouth based OHE-Southwest training school (and my mentor), believed strongly that the 'darlings of dentistry' (as she called dental nurses) were largely ignored by many practices in terms of the extra value they could bring to the practice and patients. Many dental nurses who have since studied for their NEBDN Certificate in Oral Health Education have found that the skills and knowledge they have gained from their training have also opened up exciting new career paths.

\section{Life changing experiences}

As one former student of OHE-Southwest, Helen Mathias, commented: 'The OHE course is not just about developing professionally from a registered dental nurse to an oral health educator, this course is also about growing both professionally and on a personal level, developing self confidence, self belief, and potentially leading to major life changing experiences.' Since qualifying Helen has embarked upon a successful career as an oral health tutor in professions allied to dentistry, and as a project leader of a national research project. Helen currently works at the strategic health level.

Julie Harrington and Lynn Redwoods, who are qualified OHEs working near Bristol, have used their training to work with their local community, as Julie explains: 'Lynn and I have visited our village playgroups, talking about caring for teeth, as well as our local junior school, where we spoke to all seven classes about caring for their smile. We think we must have disclosed nearly 300 children in one month and Bristol Water are probably wondering why their water is turning blue! We have also carried out initiatives during National Smile Month. We had a competition to design a healthy lunchbox and have had two articles published in the local paper about us. It has been great fun and we are thinking about painting a picture of a smiley tooth on the side of Julie's Jeep for when we are out and about.'

\section{Boosting confidence}

Some students, like Maxine Wheeler from Somerset, have found that simply running a Preventative Dental Unit in their own practice has made them feel more part of the dental team: 'The oral health education course has not only boosted my confidence in the workplace. I feel that I have gained respect from dentists and hygienists with whom I now work as part of a team educating and improving the oral health of patients.'

Other students have gone on to study dental hygiene or therapy, and some have even become Oral Health Education tutors themselves.

However, not all students receive the same level of support from dental practice teams, particularly those who have to pay for the course themselves, as certain practices do not see the benefits that a trained OHE can bring. But as Alison Chapman, a hygienist, OHESouthwest tutor and lecturer at Bristol Dental Hospital, explains, the argument for training DCPs is compelling: 'Many dentists find an oral health educator is an asset to the practice.
An OHE can complement the role of the dental hygienist, help increase sales of oral hygiene aids and promote cosmetic treatments offered by the practice. It is economical for dentists to carry out the work for which they are qualified, allowing a trained educator to help patients with prevention and control of dental disease.'

\section{Access to training}

Another barrier to nurses and DCPs becoming successful OHEs is actually gaining access to the training itself, with many finding it difficult to take time off to study, or simply too costly. For these reasons the British Dental Association (BDA) has recently developed a unique online course leading to the NEBDN Certificate. The BDA's Education Department (who already run a very successful online radiological course) recently teamed up with OHE-Southwest (which has an average pass rate of 95\%), to design a unique online OHE course for students who wish to study in their own time.

This flexible course, which runs six times a year and constitutes 40 hours of CPD, consists of 27 'bite-sized' mini-lectures. Each student is assigned a dedicated tutor who gives additional help and guidance, and can draw upon a course textbook A basic guide to oral health education and promotion (see review on page 6). Following this online study period students then work practically with patients to create a portfolio of patient care. Students have access to the course for a further four weeks before electing to take the exam in September or March.

So, it seems that there has never been a better time to train as an OHE. The health and work benefits for patients and practices is clear, but perhaps the greatest winners are the 'darlings of dentistry' who now have a real chance to become more integrated members of the dental team as well as furthering their own careers.

For more information about the BDA's online OHE course visit www.bda.org/ ohecourse or telephone 02075636891 . 